\title{
THE
}

\section{Parasitism and a Shortage of Refuges Jointly Mediate the Strength of Density Dependence in a Reef Fish}

\author{
Graham E. Forrester \\ University of Rhode Island, gforrester@uri.edu \\ Rachel J. Finley \\ University of Rhode Island
}

Follow this and additional works at: https://digitalcommons.uri.edu/nrs_facpubs

Terms of Use

All rights reserved under copyright.

\section{Citation/Publisher Attribution}

Forrester, G. E. and Finley, R. J. (2006), PARASITISM AND A SHORTAGE OF REFUGES JOINTLY MEDIATE THE STRENGTH OF DENSITY DEPENDENCE IN A REEF FISH. Ecology, 87: 1110-1115. doi: 10.1890/ 0012-9658(2006)87[1110:PAASOR]2.0.C0;2

Available at: http://dx.doi.org/10.1890/0012-9658(2006)87[1110:PAASOR]2.0.C0;2

This Article is brought to you for free and open access by the Natural Resources Science at DigitalCommons@URI. It has been accepted for inclusion in Natural Resources Science Faculty Publications by an authorized administrator of DigitalCommons@URI. For more information, please contact digitalcommons-group@uri.edu. 


\section{ECOLOGICAL SOCIETY OF AMERICA}

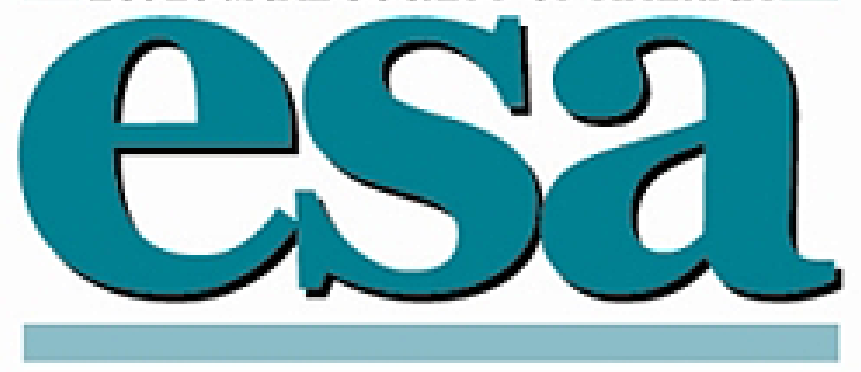

Parasitism and a Shortage of Refuges Jointly Mediate the Strength of Density Dependence in a Reef Fish

Author(s): Graham E. Forrester and Rachel J. Finley

Source: Ecology, Vol. 87, No. 5 (May, 2006), pp. 1110-1115

Published by: Ecological Society of America

Stable URL: http://www.jstor.org/stable/20069050

Accessed: 01/05/2013 11:45

Your use of the JSTOR archive indicates your acceptance of the Terms \& Conditions of Use, available at http://www.jstor.org/page/info/about/policies/terms.jsp

JSTOR is a not-for-profit service that helps scholars, researchers, and students discover, use, and build upon a wide range of content in a trusted digital archive. We use information technology and tools to increase productivity and facilitate new forms of scholarship. For more information about JSTOR, please contact support@jstor.org. 


\title{
PARASITISM AND A SHORTAGE OF REFUGES JOINTLY MEDIATE THE STRENGTH OF DENSITY DEPENDENCE IN A REEF FISH
}

\author{
Graham E. Forrester ${ }^{1}$ and Rachel J. Finley \\ Department of Natural Resources Science, University of Rhode Island, Kingston, Rhode Island 02881 USA

\begin{abstract}
Various predator-prey, host-pathogen, and competitive interactions can
\end{abstract} \\ combine to cause density dependence in population growth. Despite this possibility, most \\ empirical tests for density-dependent interactions have focused on single mechanisms. Here we \\ tested the hypothesis that two mechanisms of density dependence, parasitism and a shortage \\ of refuges, jointly influence the strength of density-dependent mortality. We used mark- \\ recapture analysis to estimate mortality of the host species, the bridled goby (Coryphopterus \\ glaucofraenum). Sixty-three marked gobies were infected with a copepod gill parasite \\ (Pharodes tortugensis), and 188 were uninfected. We used the spatial scale at which gobies were \\ clustered naturally $\left(\sim 4 \mathrm{~m}^{2}\right)$ as an ecologically relevant neighborhood and measured goby \\ density and the availability of refuges from predators within each goby's neighborhood. Goby \\ survival generally declined with increasing density, and this decline was steeper for gobies with \\ access to few refuges than for gobies in neighborhoods where refuges were common. The \\ negative effects of high density and refuge shortage were also more severe for parasitized \\ gobies than for gobies free of parasites. This parasite has characteristics typical of emerging \\ diseases and appears to have altered the strength of a preexisting density-dependent \\ interaction.
}

Key words: bridled goby; competition; coral reefs; Coryphopterus glaucofraenum; density dependence; emerging diseases; fishes; mark-recapture; mortality; parasites; predation; refuges.

\section{INTRODUCTION}

The stability of populations and their response to environmental perturbations is shaped by the strength and nature of density-dependent feedbacks in population growth (Murdoch 1994). Density dependence in population growth can have a variety of underlying biological causes, including various types of predatorprey, host-pathogen, and competitive interactions (Lomnicki 1988). Isolating these interactions and defining their effects on natural populations remains a major challenge in population ecology (Turchin 1999, Krebs 2002). One source of difficulty arises from the possibility that multiple density-dependent interactions might operate simultaneously (May 1983, den Boer and Reddingius 1996, Polis et al. 1998, Krebs 2002). Despite this possibility, for practical reasons, most attempts to identify and quantify the influence of density-dependent interactions have focused on single mechanisms (Holmes 1995).

Here we focus on the possibility that two mechanisms of density dependence, parasitism and competition for refuges, might combine to influence the strength of density-dependent mortality. Either of these mechanisms in isolation has the potential to induce density dependence, though there are relatively few experimen-

Manuscript received 29 September 2005; revised 14 December 2005; accepted 14 December 2005. Corrresponding Editor: P. T. Raimondi.

${ }^{1}$ E-mail: gforrester@uri.edu tal field studies that provide support for either hypothesis. Many animals use structural features of their habitat to take refuge when threatened or attacked by predators. When the number of such shelters is limited, mortality inflicted by predators is likely to increase as prey density increases (Murdoch and Oaten 1975). Competition for a limited supply of refuges is thus a potentially widespread cause of density-dependent mortality, and cross-factored manipulations of refuge availability and density provide direct support for this hypothesis (e.g., Seitz et al. 2001, Holbrook and Schmitt 2002, Forrester and Steele 2004 and references therein).

There is also a handful of studies showing that parasites can inflict density-dependent mortality and/or fecundity in nature (Tompkins and Begon 1999) and, in two of these cases, this density dependence is sufficient to regulate wild-host populations (Hudson et al. 1998, Albon et al. 2002). The paucity of evidence for parasiteinduced density dependence is partly because experimentally infecting or disinfecting populations to properly isolate the effect of parasitism is difficult in nature (Tompkins and Begon 1999). Identifying infected hosts nondestructively and tracking their fates is also difficult in many systems (Plowright 1988).

Interactive effects of parasitism and a shortage of refuges that mediate the strength of density dependence are plausible (Hassell 1982), especially since parasiteinduced changes in host behavior can affect a host's susceptibility to predators and/or its competitive ability (Barber et al. 2000). We used a study species for which 
TABLE 1. Census details and release dates of marked gobies.

\begin{tabular}{|c|c|c|c|c|c|}
\hline \multirow[b]{2}{*}{ Census } & \multirow[b]{2}{*}{ Census date } & \multirow{2}{*}{$\begin{array}{l}\text { No. gobies } \\
\text { censused }\end{array}$} & \multirow{2}{*}{$\begin{array}{c}\text { Parasite } \\
\text { prevalence } \\
(\%)\end{array}$} & \multicolumn{2}{|c|}{ No. gobies marked } \\
\hline & & & & Unparasitized & Parasitized \\
\hline 1 & 28 Aug-1 Sep & 1823 & 8.9 & 70 & 16 \\
\hline 2 & 9-12 Sep & 1565 & 10.4 & 60 & 18 \\
\hline 3 & $22-25$ Sep & 1166 & 7.8 & 54 & 18 \\
\hline 4 & $7-9$ Oct & 964 & 13.2 & 4 & 11 \\
\hline 5 & 14-17 Oct & 834 & 13.9 & 0 & 0 \\
\hline 6 & $21-23$ Oct & 852 & 8.9 & 0 & 0 \\
\hline
\end{tabular}

Note: The study was conducted at a shallow site on the wave-protected south side of Guana Island, British Virgin Islands.

field experiments show that individuals have progressively diminishing access to refuges as they become crowded. Crowded individuals are more vulnerable to predation than those at lower density, which leads to density-dependent mortality (Forrester and Steele 2000, 2004). Mortality of this species is also increased by infection with a common macroparasite (Finley and Forrester 2003). This system thus provided the opportunity to test the hypothesis that parasitism increases the strength of density-dependent mortality by exacerbating the effects of refuge shortage.

\section{Methods}

\section{The study system}

The host species, the bridled goby (Coryphopterus glaucofraenum Gill), is a small, benthic, reef fish that is common throughout the Caribbean. Like most reef fishes, bridled gobies produce pelagic larvae. Larvae settle to reef habitats at $6.5-8 \mathrm{~mm}$ standard length (SL) after roughly $30 \mathrm{~d}$ in the plankton. Juveniles mature into females at 22-25 mm SL and can change sex to become males at $\sim 30 \mathrm{~mm} \mathrm{SL}$ (Cole and Shapiro 1992). The largest individuals reach $50-55 \mathrm{~mm} \mathrm{SL}$, and very few live beyond a year. Bridled gobies occupy small, stable home ranges $\left(\sim 2 \mathrm{~m}^{2}\right)$ in areas of interspersed sand and reef. $A$ mix of sand and reef is required because they feed on sand-dwelling invertebrates, but use crevices at the reef/ sand interface as temporary refuges when threatened or attacked by predators (Forrester and Steele 2004).

The pathogen is a parasitic copepod (Pharodes tortugensis Wilson), which commonly infects the gill cavity of bridled gobies. This copepod is reported to infect other fish species (Ho 1971), but at our study site was only found infecting bridled gobies and two ecologically similar congeners, $C$. dicrus and $C$. eidolon Böhlke \& Robins (Petrik-Finley 2005). Parasites were never found on newly settled gobies, suggesting that gobies become infected only after settling to the reef. The parasite has a direct life cycle and can infect new hosts soon after hatching. Laboratory studies show that parasites are transmitted among neighboring gobies, but the rate of transmission is quite low, and a correlation between host density and transmission was not detectable statistically (Petrik-Finley 2005). Infection intensity increases with fish size, and a typical infection consists of several smaller male and juvenile copepods and 1-2 larger females. Most infected fish (65\%) were intermediate in size, $15-30 \mathrm{~mm} \mathrm{SL}$, and very few fish $>35 \mathrm{~mm} \mathrm{SL}$ were infected (Petrik-Finley 2005).

This study was done at a shallow $(5-7 \mathrm{~m})$ site on the wave-protected south side of Guana Island, British Virgin Islands $\left(18^{\circ} 29^{\prime} \mathrm{N}, 64^{\circ} 35^{\prime} \mathrm{W}\right)$. The site comprised a rectangular area of mixed sand and reef $(30 \times 26 \mathrm{~m})$ embedded within a larger expanse of similar habitat. To facilitate censusing gobies and mapping habitat, we placed markers to subdivide the site into a $2 \times 2 \mathrm{~m}$ lattice.

\section{Mark-recapture protocols}

A sample of gobies resident within the site was marked in situ and released on each of four dates in 2003 (Table 1). Gobies were captured using hand nets and anesthetic (Quinaldine; Sigma-Aldrich, St. Louis, Missouri, USA) and measured using calipers. Fish $<25 \mathrm{~mm}$ SL were marked by subcutaneous injection of a small spot of colored elastomer, whereas larger gobies were injected with a coded plastic tag $(1 \times 2.5 \mathrm{~mm}$; Malone et al. 1999). Gobies were released back into their home ranges within 5 min of capture. All marked gobies were recognizable as individuals, and divers could view the marks without recapturing the fish. Gobies for marking were selected at random, with restrictions based on the fact that only gobies $>15 \mathrm{~mm}$ SL can be marked without side effects and on the need to obtain a sample representative of the size range commonly infected with parasites. We also ensured that gobies were sampled from all parts of the site and that we obtained an adequate sample of parasitized fish. We marked 63 gobies with parasites and 188 without, ranging in initial size from 14.5 to $38.4 \mathrm{~mm} \mathrm{SL}$ (mean $=22.2 \mathrm{~mm} \mathrm{SL}$ ).

\section{Defining the density and refuge availability experienced by each marked fish}

We censused the entire goby population at the site on six occasions spread over $56 \mathrm{~d}$ in 2003 (Table 1). Each census took 3-4 d to complete. Using the lattice markers as a guide, the location of each goby was recorded on a map of the site and later assigned a Cartesian coordinate $(x, y)$. We also made a visual diagnosis of the presence or 
absence of parasites. Visual diagnosis of infection status was based on the fact that infected gobies have a distended operculum. Previously, we captured and dissected fish after making these visual diagnoses, which showed that $93 \%$ of uninfected fish were correctly diagnosed (111 of 120 correct), whereas diagnosis of infected fish was $85 \%$ accurate (57 of 67 correct). Most errors in diagnosis occurred because fish infected with a few small copepods are hard to distinguish from parasite-free fish (Petrik-Finley 2005).

In a companion study at our study site, spatial statistical models (Ripley's $K$ ) revealed strong clustering of gobies in patches $\sim 4 \mathrm{~m}^{2}$ (Petrik-Finley 2005). We therefore used a "neighborhood" of this size to characterize the density experienced by each marked fish. For each marked goby, we calculated the number of conspecifics within a $2 \times 2 \mathrm{~m}$ area centered on the midpoint of its home range. Densities were calculated for each date on which the goby was alive, and we used the time-averaged density when testing for densitydependent mortality.

Crevices suitable for use as refuges by gobies are usually at the junction between sand patches $\left(\geq 0.4 \mathrm{~m}^{2}\right.$ in area) and rocks ( $>5 \mathrm{~cm}$ diameter) or corals. To estimate the density of refuges available to each marked goby, we mapped habitat within the site on 13 and 18 October 2003. Divers hovered over each $2 \times 2 \mathrm{~m}$ subsection of the site and sketched the outline of all rocks $(>5 \mathrm{~cm}$ diameter) and corals. A grid of 250 regularly arrayed points was overlain on each sketch and the type of substratum under each point noted. We again centered a $2 \times 2 \mathrm{~m}$ window over the midpoint of each goby's home range and used the array of points to calculate the percent cover of rock/coral within the neighborhood of each marked goby. Previous surveys revealed a humpshaped relationship between refuge density $(y)$ and the percent cover of rock/coral $(x)$, which peaks at $\sim 40 \%$ cover (G. E. Forrester, unpublished data). We thus used piecewise linear regressions to predict refuge density (number per square meter) within the neighborhood of each marked goby (for $0-40 \%$ cover, $y=0.72+0.14 x, n$ $=280, r^{2}=0.59$; for $>40-80 \%$ cover, $y=11.6-0.12 x, n=$ $22, r^{2}=0.37$; for $>80 \%$ cover, $y=0, n=6$ ).

\section{Modeling survival and resighting probabilities}

We used the resighting histories of marked individuals to model survival $(\phi)$ and resighting probabilities $(p)$ (Lebreton et al. 1992). Individual gobies constitute replicates in all models. Our primary goal was to model the effects of goby density (density), the density of refuges (refuges), and infection status (parasitism) on survival. We also examined the effect of body size (size) because, although not of specific interest, survival is often lower in small fish than larger ones. We used the logit link function to incorporate these predictor variables into models and used the small sample version of Akaike's information criterion $\left(\mathrm{AIC}_{\mathrm{c}}\right)$ and evidence ratios $\left(w_{i} / w_{j}\right)$ calculated from Akaike weights $(w)$ to evaluate model fit (Burnham and Anderson 2002).

Evaluating the effect of parameters of interest on survival from mark-recapture data requires first identifying an acceptable starting model (notation $\phi(x) p(y)$ ) and then controlling any biases in resighting probability. Since parasitism is a binary variable and we know that parasites affect goby survival (Finley and Forrester 2003), we constructed all models separately for fish with and without parasites. Our data failed to meet the assumption of the widely used Cormack-Jolly-Seber (CJS) starting model, which allows $\phi$ and $p$ to vary relative to parasitism and time $(t)$. We therefore developed an alternate starting model that adequately described the data (for details see the Appendix). The alternate starting model grouped time intervals into two categories based on time since marking (TSM): one for the interval after the fish was marked and another for all subsequent intervals $(\phi[$ parasitism $\times \mathrm{TSM}] p[$ parasitism $\times$ TSM]). Analysis of bias in resighting probability revealed that $p$ was affected by goby density, so we used the model $\phi($ parasitism $\times$ TSM $) p($ parasitism $\times$ TSM + density) as a starting point from which to test effects of the covariates on survival (for details of the analysis of bias in $p$, see the Appendix).

Our starting model for $\phi$, expressed in the form of a linear model, is $\operatorname{Logit}(\phi)=\beta_{0}+\beta_{1}$ (TSM) $+\beta_{2}$ (parasitism $)+\beta_{3}$ (parasitism $\times$ TSM). We know from our previous work that parasitism, density, and refuges all affect goby survival and that effects of density and refuges interact (Finley and Forrester 2003, Forrester and Steele 2004). In this study, we are primarily interested in whether there are additional interactive effects involving parasitism. Therefore, all our candidate models include effects of parasitism, density, refuges, and density $\times$ refuges. We then considered progressively more complex models by adding two-way interactions (parasitism $\times$ density and parasitism $\times$ refuges), first singly, then both together. Lastly we added the threeway interaction (parasitism $\times$ density $\times$ refuges; Table 2). We hypothesized that there would be a three-way interaction because the strength of density-dependent survival would be increased where refuges were less dense, and this increase would be more pronounced for parasitized fish than for fish lacking parasites. Finally, we also evaluated models containing effects of body size, but found that survival could be adequately modeled without including its effect (for details of the analysis of body size on survival see the Appendix).

\section{RESUlts}

Of our candidate models describing effects of parasitism, density, and refuges on survival, the model with most support in the data was the most complex model (model 1), which contained a term for the three-way interaction between these factors (Table 2). Based on the evidence ratios, this model had 3.2 times more support than the next most likely model (Table 2). The second 
TABLE 2. Candidate mark-recapture models screened for effects of infection status (parasitism), goby density (density), refuge availability (refuges), and time since marking (TSM) on survival $(\phi)$.

\begin{tabular}{|c|c|c|c|c|c|}
\hline Model & & $\mathrm{AIC}_{\mathrm{c}}$ & $\Delta \mathrm{AIC}_{\mathrm{c}}$ & $w_{\mathrm{i}}$ & np \\
\hline 1 & $\begin{array}{l}\phi(\text { parasitism }+ \text { TSM }+[\text { parasitism } \times \text { TSM }] \\
\quad+\text { density }+ \text { refuges }+[\text { density } \times \text { refuges }] \\
\quad+[\text { parasitism } \times \text { density }+[\text { parasitism } \times \text { refuges }] \\
\quad+\text { [parasitism } \times \text { density } \times \text { refuges }])\end{array}$ & 933.6 & 0 & 0.713 & 14 \\
\hline 2 & $\begin{array}{l}\phi(\text { parasitism }+ \text { TSM }+[\text { parasitism } \times \text { TSM }] \\
\quad+\text { density }+ \text { refuges }+[\text { density } \times \text { refuges }] \\
\quad+[\text { parasitism } \times \text { density }]+[\text { parasitism } \times \text { refuges }])\end{array}$ & 935.9 & 2.33 & 0.222 & 13 \\
\hline 3 & $\begin{array}{l}\phi(\text { parasitism }+ \text { TSM }+[\text { parasitism } \times \text { TSM }]+\text { density } \\
\quad+\text { refuges }+[\text { density } \times \text { refuges }]+[\text { parasitism } \times \text { density }])\end{array}$ & 938.7 & 5.14 & 0.055 & 12 \\
\hline 4 & $\begin{array}{l}\phi(\text { parasitism }+ \text { TSM }+[\text { parasitism } \times \text { TSM }]+\text { density } \\
\quad+\text { refuges }+[\text { density } \times \text { refuges }]+[\text { parasitism } \times \text { refuges }])\end{array}$ & 943.9 & 10.28 & 0.004 & 12 \\
\hline 5 & $\begin{array}{l}\phi(\text { parasitism }+ \text { TSM }+[\text { parasitism } \times \text { TSM }] \\
\quad+\text { density }+ \text { refuges }+[\text { density } \times \text { refuges }])\end{array}$ & 943.4 & 9.83 & 0.005 & 11 \\
\hline 6 & $\begin{array}{l}\phi(\text { parasitism }+ \text { TSM }+[\text { parasitism } \times \text { TSM }] \\
\quad+\text { density }+ \text { refuges })\end{array}$ & 947.7 & 14.15 & 0.0006 & 10 \\
\hline 7 & $\phi($ parasitism $+\mathrm{TSM}+[$ parasitism $\times \mathrm{TSM}])$ & 958.4 & 24.82 & $<0.0001$ & 8 \\
\hline
\end{tabular}

Notes: $\triangle \mathrm{AIC}_{\mathrm{c}}$ is the difference in the corrected Akaike Information Criterion $\left(\mathrm{AIC}_{\mathrm{c}}\right)$ between the lowest $\mathrm{AIC}_{\mathrm{c}}$ and $\mathrm{AIC}_{\mathrm{c}}$ of model $i$; the Akaike weight $\left(w_{i}\right)$ is the weight of evidence in favor of model $i$; $\mathrm{np}$ is the number of parameters. For all models, resighting probability is modeled as $p$ ([parasitism $\times$ TSM] + density).

most likely model was model 2 , which included both of the two-way interactions involving parasitism (Table 2). Model 2, in turn, had at least 4.1 times as much support as any of the simpler models considered (Table 2). Although there is perhaps not strong enough evidence to strongly favor model 1 over model 2 , it seems safe to conclude that these two models are far better supported than any of the simpler models. Our main finding is thus that the effect of parasitism on survival is conditional both on goby density and on refuge availability.

To visualize the biologically interesting two- and three-way interactions revealed by the modeling of $\phi$, we reconstituted parameter values from the final model. Plots of the parameter values indicate that the effect of parasitism is reduced when refuges are more common (Fig. 1a). The survival of gobies generally declines as their density increases, and the strength of density dependence is generally greater for fish with parasites than without (Fig. 1b) and greater in areas with fewer refuges (not shown). The three-way interaction appears to arise, however, because the increased strength of density-dependent survival in areas with fewer refuges is much more pronounced for parasitized fish than for fish lacking parasites (Fig. 1c, d).

\section{Discussion}

Although previous experimental work confirms a causal link between the effects of refuge availability and goby density on survival (Forrester and Steele 2004), we have no experimental evidence to indicate a causal relationship between parasitism and mortality. Because we tracked the fate of gobies with and without parasites, both in this study and in previous studies of $P$. tortugensis impacts (Finley and Forrester 2003, Petrik-Finley 2005), we can be sure that an effect associated with parasitism influences goby mortality. However, since both studies are correlational, the possibility of a spurious association between parasitism and mortality remains. Keeping this caveat in mind, our results suggest that parasitism increases the strength of density-dependent mortality by exacerbating the effect of refuge shortage.

Our results do not, however, tell us precisely how the presence of parasites alters the gobies' interactions with predators and with refuges. The two main possibilities are that parasitized fish are poorer competitors for access to refuges or are simply targeted more effectively by predators than their parasite-free neighbors. There are a variety of behavioral changes induced by parasites that might lead to parasitized fish becoming poor competitors or selectively consumed by predators (Barber et al. 2000). Most predation on gobies is inflicted by larger fishes (Forrester and Steele 2000), and copepods carried by the goby are unlikely to be transmitted to a predatory fish that consumes a goby. Predation is not, therefore, a means by which parasites move from an intermediate to definitive host (Lafferty and Morris 1996). If predators selectively consume parasitized gobies, we suspect this is a simple consequence of parasitized gobies being easy to detect or capture (Lafferty 1992). Another possibility is that parasitized gobies are less able to secure access to refuges than the unparasitized gobies with whom their home ranges overlap. Aggression among gobies is more frequent as they become crowded (Forrester et al., in press), and agonistic encounters may have a role in securing access to refuges. The ratio of wins:losses in aggressive encounters $(n=41)$ is slightly lower in parasitized gobies $(1.29: 1)$ than in unparasitized gobies $(1.44: 1)$, but more samples would be required to 

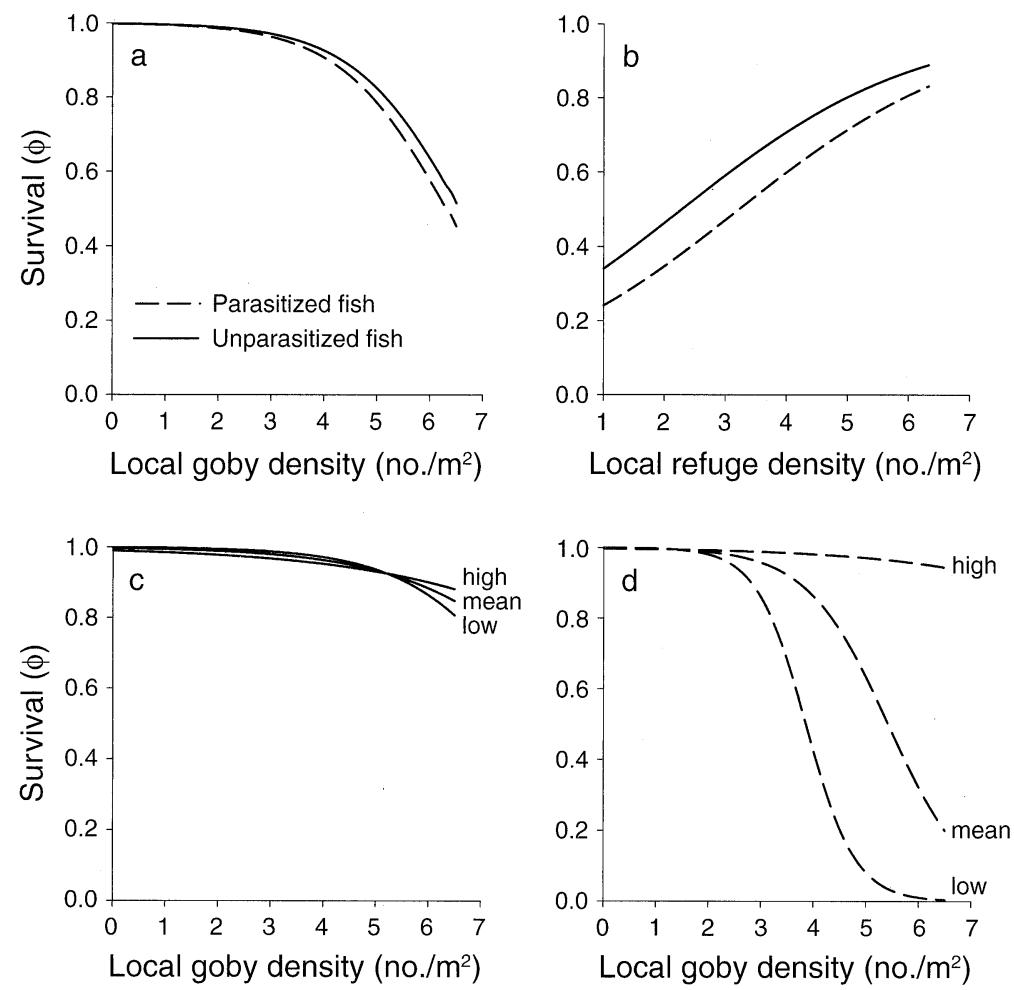

FIG. 1. Reconstituted parameter values from the final mark-recapture model to illustrate the interactive effects of parasitism, goby density, and refuge density on survival. (a) The two-way interaction between parasitism and density. (b) The two-way interaction between parasitism and refuges. (c, d) The three-way interaction among parasitism, density, and refuges. Separate plots are drawn for fish experiencing the lowest (0.86), mean (3.66), and highest (6.32) refuge density (number of crevices per square meter) at the site: (c) unparasitized fish; (d) parasitized fish. The study was conducted at a shallow site on the wave-protected south side of Guana Island, British Virgin Islands.

rigorously test whether parasitized fish lose out in competition for refuges (Finley and Forrester 2003).

Recent decades have seen dramatic increases in the number of reports of diseases affecting wildlife, both in terrestrial (Daszak et al. 2000) and marine habitats (Harvell et al. 1999). Although its distribution, host range, and prevalence is little studied, $P$. tortugensis has the characteristics of an "emerging" disease in the sense described by Daszak and colleagues (Daszak et al. 2000). Around Guana Island, the prevalence of $P$. tortugensis on C. glaucofraenum has increased markedly from $<3 \%$ in 1993-1994 to an average close to $20 \%$ from 2003 to 2005 (G. Forrester and R. Finley, unpublished data). In contrast, the prevalence of $P$. tortugensis has remained extremely low $(<0.05 \%)$ over the past 10 years at Lee Stocking Island, Bahamas, the other site at which we have studied C. glaucofraenum intensively (G. Forrester and M. Steele, unpublished data). A shortage of refuges from predation causes density-dependent mortality at both Lee Stocking Island and Guana Island (Forrester and Steele 2004). The emergence of wildlife diseases, both on land and in the ocean, has often been associated with increases in host mortality (Harvell et al. 1999, Daszak et al. 2000), and our previous work at Guana Island revealed that copepod parasitism was associated with a doubling of the instantaneous mortality rate in bridled gobies (Finley and Forrester 2003). This study shows, however, that the impact of parasitism depends strongly on the local density of gobies and on the local availability of refuges. The increased prevalence of this copepod parasite at Guana Island thus appears to have intensified the effect of a preexisting density-dependent interaction. Parasite prevalence is currently high enough around Guana Island $(\sim 20 \%)$ that this intensification of density dependence could increase the overall regulation of the goby population.

Some workers have argued that we should expect density-dependent interactions to be complex, with multiple underlying causes that vary in the strength of their effects in space and time (Holmes 1995). We are, however, aware of few documented examples (Hansen et al. 1999, Rodenhouse et al. 2003), only one of which involves parasitism. In that case, a severe die-off of Soay sheep was apparently due to an interaction between effects of a parasite and a shortage food (Gulland 1992). To the best of our knowledge, the specific effect of parasitism we describe in this study has not been previously documented. In light of the continuing increase in disease outbreaks in the ocean (Ward and 
Lafferty 2004), it is important to further document the effects of emerging diseases on species interactions.

\section{ACKNOWLEDGMENTS}

Many thanks to Danielle Ameen, Brent Finley, Elizabeth Kintzing, and Linda Forrester for help with field work, to Richard Zabel for advice on mark-recapture models, to the reviewers for their constructive suggestions, and to Lianna Jarecki and the staff at Guana Island for logistical support. Financial support was provided by the National Science Foundation (OCE 0222087), the Guana Island Wildlife Sanctuary, and the Falconwood Corporation.

\section{Literature Cited}

$\rightarrow$ Albon, S. D., A. Stien, R. J. Irvine, R. Langvatn, E. Ropstad, and O. Halvorsen. 2002. The role of parasites in the dynamic of a reindeer population. Proceedings of the Royal Society Biological Sciences Series B 269:1625-1632.

Barber, I., D. Hoare, and J. Krause. 2000. Effects of parasite: on fish behaviour: a review and evolutionary perspective. Reviews in Fish Biology and Fisheries 10:131-165.

Burnham, K. P., and D. R. Anderson. 2002. Model selection and inference - a practical information-theoretic approach. Second edition. Springer-Verlag, New York, New York, USA.

Cole, K. S., and D. Y. Shapiro. 1992. Gonadal structure and population characteristics of the protogynous goby Coryphopterus glaucofraenum. Marine Biology 113:1-9.

$\rightarrow$ Daszak, P., A. A. Cunningham, and A. D. Hyatt. 2000. Wildlife ecology - emerging infectious diseases of wildlife - threats to biodiversity and human health. Science 287:443-449.

den Boer, P. J., and J. Reddingius. 1996. Regulation anc' stabilization paradigms in population ecology. Chapman and Hall, London, UK.

Finley, R. J., and G. E. Forrester. 2003. Impact of ectoparasites on the demography of a small reef fish. Marine Ecology Progress Series 248:305-309.

Forrester, G. E., B. Evans, M. Steele, and R. Vance. In press. Assessing the magnitude of intra- and interspecific competition in two coral reef fishes. Oecologia.

$\rightarrow$ Forrester, G. E., and M. A. Steele. 2000. Variation in the presence and cause of density-dependent mortality in thre species of reef fishes. Ecology 81:2416-2427.

$\rightarrow$ Forrester, G. E., and M. A. Steele. 2004. Predators, prey refuges, and the spatial scaling of density-dependent prey mortality. Ecology 85:1332-1342.

Gulland, F. M. D. 1992. The role of nematode parasites in soay sheep (Ovis-Aries L) mortality during a population crash. Parasitology 105:493-503.

$\rightarrow$ Hansen, T. F., N. C. Stenseth, H. Henttonen, and J. Tast. 1999. Interspecific and intraspecific competition as causes of direc and delayed density dependence in a fluctuating vole population. Proceedings of the National Academy of Sciences (USA) 96:986-991.

$\rightarrow$ Harvell, C. D. et al. 1999. Emerging marine diseases climate links and anthropogenic factors. Science 285:1505-1510.

Hassell, M. P. 1982. Impact of infectious diseases on host populations. Pages 15-35 in R. M. Anderson and R. M. May, editors. Population biology of infectious diseases. Springer Verlag, New York, New York, USA.
Ho, J. S. 1971. Pharodes Wilson, 1935, a genus of cyclopoid copepods (Pharodidae) parasitic on marine fishes. Journal of Natural History 5:349-359.

$\rightarrow$ Holbrook, S. J., and R. J. Schmitt. 2002. Competition for shelter space causes density-dependent predation mortality in damselfishes. Ecology 83:2855-2868.

Holmes, J. C. 1995. Population regulation: a dynamic complex of interactions. Wildlife Research 22:11-19.

Hudson, P. J., A. P. Dobson, and D. Newborn. 1998. Prevention of population cycles by parasite removal. Science 282:2256-2258.

Krebs, C. J. 2002. Two complementary paradigms for analysing population dynamics. Philosophical Transactions of the Royal Society of London B, Biological Sciences 357:1211-1219.

$\rightarrow$ Lafferty, K. D. 1992. Foraging on prey that are modified by parasites. American Naturalist 140:854-867.

Lafferty, K. D., and A. K. Morris. 1996. Altered behavior of parasitized killifish increases susceptibility to predation by bird final hosts. Ecology 77:1390-1397.

Lebreton, J.-D., K. P. Burnham, J. Clobert, and D. R. Anderson. 1992. Modeling survival and testing biological hypotheses using marked animals: a unified approach with case studies. Ecological Monographs 62:67-118.

Lomnicki, A. 1988. Population ecology of individuals. Princeton University Press, Princeton, New Jersey, USA.

Malone, J. C., G. E. Forrester, and M. A. Steele. 1999. Effects of subcutaneous microtags on the growth, survival, and vulnerability to predation of small reef fishes. Journal of Experimental Marine Biology and Ecology 237:243-253.

May, R. M. 1983. Parasitic infections as regulators of animal populations. American Scientist 71:36-45.

Murdoch, W. W. 1994. Population regulation in theory and practice. Ecology 75:271-287.

Murdoch, W., and A. Oaten. 1975. Predation and population stability. Advances in Ecological Research 9:1-132.

Petrik-Finley, R. J. 2005. The impact of a gill copepod on the demography of a reef fish host. Dissertation. University of Rhode Island, Kingston, Rhode Island, USA.

Plowright, W. L. 1988. Research on wildlife diseases: is a reappraisal necessary? Revue Scientifique et Technique de l'Office International des Epizooties 7:783-795.

Polis, G. A., S. D. Hurd, C. T. Jackson, and F. Sanchez-Pinero. 1998. Multifactor population limitation: variable spatial and temporal control of spiders on Gulf of California islands. Ecology 79:490-502.

$\rightarrow$ Rodenhouse, N. L., T. S. Sillett, P. J. Doran, and R. T. Holmes. 2003. Multiple density-dependence mechanisms regulate a migratory bird population during the breeding season. Proceedings of the Royal Society Series B Biological Sciences 270:2105-2110.

Seitz, R. D., R. N. Lipcius, A. H. Hines, and D. B. Eggleston. 2001. Density-dependent predation, habitat variation, and the persistence of marine bivalve prey. Ecology 82:2435-2451.

Tompkins, D. M., and M. Begon. 1999. Parasites can regulate wildlife populations. Parasitology Today 15:311-313.

Turchin, P. 1999. Population regulation: a synthetic view. Oikos 84:153-159.

Ward, J. R., and K. D. Lafferty. 2004. The elusive baseline of marine disease: Are diseases in ocean ecosystems increasing? Public Library of Science: Biology 2:542-547.

\section{APPENDIX}

A description of the initial modeling of survival and resighting probabilities (Ecological Archives E087-063-A1). 